\title{
Thumb Opposition Strength in Healthy Adults- A Baseline Study
}

\section{Charles Andrew R Chu-Santos ${ }^{1}$ and Precious Grace B Handog ${ }^{2 *}$}

${ }^{1}$ Department of Orthopaedics, Chong Hua Hospital Cebu, Philippines

${ }^{2}$ Hand and Reconstructive Microsurgery, Department of Orthopaedics, Chong Hua

Hospital Cebu, Philippines

*Corresponding Author: Precious Grace B Handog, Hand and Reconstructive

Microsurgery, Department of Orthopaedics, Chong Hua Hospital Cebu, Philippines.
Received: May 12, 2021

Published: May 28, 2021

(C) All rights are reserved by Charles

Andrew R Chu-Santos and Precious Grace

B Handog.

\section{Abstract}

Background: The thumb is considered the central component of hand function and involves for $40 \%$ to $50 \%$ of the hand's usefulness. Thumb opposition is the hallmark of human hand function and is the most important motion of the hand. Currently there is no quantitative baseline data for thumb opposition strength using a standardized measure and tool. Thus, this study aims to provide the baseline reference using the Jamar B \& L Pinch Gauge Dynamometer.

Methods: Purposive sampling was done for recruitment. The maximal strength among three trials for each stage of Kapandji that was designated (Stage 5, 6, 9) was recorded and used in the data.

Results: With 388 individuals included in the study, it was noted that the mean thumb opposition strength in stage 5 right is 4.14 to $4.42 \mathrm{~kg}$, Left 3.79 to $4.04 \mathrm{~kg}$. Stage 6 right 2.80 to $3.02 \mathrm{~kg}$, Left 2.48 to $2.67 \mathrm{~kg}$. Stage 9 right 3.23 to $3.40 \mathrm{~kg}$, left 3.17 to $3.34 \mathrm{~kg}$. There was significant difference between the 3 designated stages of Kapandji (Stage 5, 6, 9). Generally, males have higher strength than females and that hand dominance has no significant correlation. Age has a positive correlation with thumb opposition strength. BMI and Dash score showed no significant correlation except on Stage 5 left and Stage 6 right.

Conclusion: Baseline reference for thumb opposition strength in the local setting in the Philippines is of significance considering that this function of the thumb is vital and it is involved in several conditions. This data will be of great importance as a quantitative measure for therapeutic assessment and that it can be used as a screening measure for susceptible individuals.

Keywords: Thumb Opposition Strength; Thenar Muscles; Dynamometer; Pinch Strength; Baseline Study

\section{Abbreviations}

DASH: Disabilities of the Arm, Shoulder, and Hand; BMI: Body Mass Index

\section{Introduction}

The thumb is considered the central component of hand function and involves for $40 \%$ to $50 \%$ of the hand's usefulness. Its function is complex compared to other fingers. It involves Flexion, Extension, palmar abduction, retroposition, adduction, and opposition [1]. Among these, thumb opposition is the hallmark of human hand function and is the most important motion of the hand and it requires a congruent saddle-shaped carpometacarpal joint, the thenar muscles, and the median nerve [2]. 
There are several conditions that would affect the thumb opposition. Severe carpal tunnel syndrome and thumb CMC joint arthritis are among the few. Procedures such as tendon transfers and opponensplasties can benefit objective postoperative monitoring of thumb opposition as well.

Some measuring tools were used to measure the function of thumb. Manual muscle strength testing by the Medical Research Council uses the muscle grades by gravity. Another tool is the Rotterdam Intrinsic myometer that measures the intrinsic muscles of the hand. Kapandji also utilizes 10 points for opposition of the thumb which will be used in this study as part of the inclusion criteria.

Currently there is no quantitative baseline data for thumb opposition strength using a standardized measure and tool. Thus, this study aims to provide the baseline reference.

The general objective of this study is to have a quantitative baseline thumb oppositional strength of Filipinos aged 21 to 60 years. The specific objectives are to correlate oppositional thumb strength to age, hand dominance, BMI and Quick DASH scores and to compare male from female data, dominant from non-dominant hand data.

This study will be using the Jamar B \& L Pinch Gauge Dynamometer (Sammons Preston Rolyan) (Figure 1) which is known as the gold standard in pinch strength (Key, Tip, and Palmar) measurement. It measures 0-60 lbs. in $2.0 \mathrm{lb}$. increments and kilogram scale. Calibration certificate included with accuracy $=0.6 \mathrm{lb}$. This will be used in this study as a standard tool.

These anthropometric data are also of paramount importance in assessing results and effectiveness of various surgical and nonsurgical treatment of hand injuries when compared to the healthy population. This data can also be of future reference for screening susceptible individuals.

Normative data are needed to interpret and evaluate data, to set realistic goals and to assess a patient's ability to return to employment.

\section{Materials and Methods}

This is a cross sectional study wherein individuals were recruited from different group of population from August 2020 to Octo- ber 2020. Purposive sampling was used which is a non-probability sampling where the sample is selected based on the inclusion criteria specified. All patients 21 to 60 -year-old that are healthy with no other hand problems and should have achieve at least stage 9 in Kapandji scoring of thumb opposition were included in the study. Those who were diagnose with: History of stroke, Connective tissue or metabolic disease, Peripheral nerve disease, Brachial plexus injury, Cervical radiculopathy, Spinal cord injury or trauma, Previous hand or upper extremity surgery or trauma, and Osteoarthritis of the hands were excluded. The sample size was computed using the Cochran's sample size formula with 95\% confidence with the calculated minimum sample size of 385 .

The conduct of the study was implemented upon approval by the Institutional Review Board and the Office of the Medical Director. Screening of participants consisted of a designed self-administered questionnaire to collect personal and demographic information. Participants who answered positively on the exclusion criteria listed were not included in the study. Participants then read and signed an informed consent. Weight and height were obtained using standard techniques and were recorded in $\mathrm{kg}$ and centimeters, respectively. BMI was calculated following the measurement of each participant's weight and height. Participants then were asked to answer the Quick Disabilities of the Arm, Shoulder and Hand (DASH).

The participant were seated with his/her shoulder adducted and neutrally rotated, elbow flexed at $90^{\circ}$ and the forearm in neutral position, wrist in $0^{\circ}-30^{\circ}$ dorsiflexion, and $0^{\circ}-15^{\circ}$ degrees ulnar deviation. This position is recommended by the American Society of Hand Therapists in examining the hand.

Kapandji staging for opposition of the hand was used. Participant should reach at least stage 9 (Tip of the thumb to the palmar metacarpophalangeal joint of small finger) as part of the inclusion criteria. The Jamar B \& L Pinch Gauge Sammons Preston Rolyan (See figure 1) was used in the study to test the thumb opposition strength. All the finger should be in relaxed neutral position. During the procedure, the thumb interphalangeal joint should be fully extended and the tip of the thumb should actively oppose to three sites: 1) tip of the ipsilateral ring finger - Kapandji Stage 5 2) tip of the ipsilateral little - Kapandji Stage 6 3) Metacarpophalangeal joint of ipsilateral small finger - Kapandji Stage 9 (See figure 2). 
The subject was asked to give maximum effort, keeping the arm in the same position. Three trials for each position were conducted. Each contraction should occur over a four to five second duration with a one second transition period at the start of the contraction. At least ten seconds of rest should be provided between stages to minimize fatigue effects. The same procedure will be done on the contralateral hand.

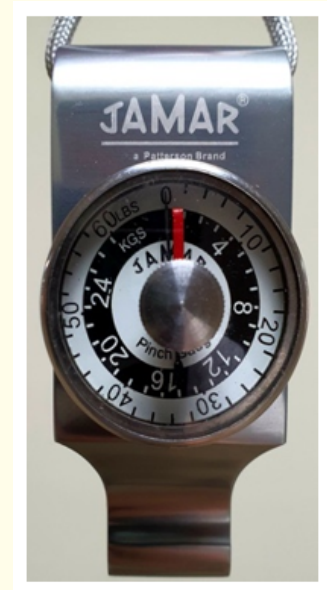

Figure 1: Jamar B \& L pinch gauge (Sammons Preston Rolyan).

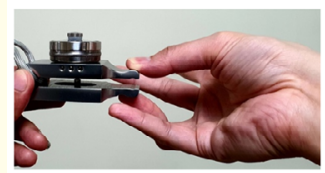

A

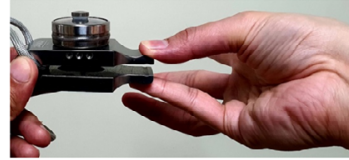

B

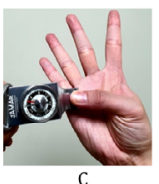

Figure 2: A, Kapandji Stage 5. B, Kapandji Stage 6. C, Kapandji Stage 9.
All data were gathered and was analyzed. The maximal strength among 3 trials for each stage of Kapandji that was designated (Stage $5,6,9$ ) was recorded and used in the data.

The researcher and a trained research assistant were the only individuals conducting this study. Only one Dynamometer was used in this study.

\section{Results}

Following screening and recruitment from August to October 2020, there were 388 individuals recruited from hospital staff and visitors including other different population group in Cebu City. There were 233 males and 155 female aged 21 to 60 years (mean: 32.57 years). $88.14 \%$ (342 out of 388) were right-hand dominant, $11.08 \%$ ( 43 out of 388 ) were left hand dominant, and $0.77 \%$ (3 out of 388) were ambidextrous. Age groups were identified as clusters and $49 \%$ of the population was on 20 - 29 age group (See figure 3). The occupation of each sample was also noted and divided as seen in figure 4 to those who were medical professionals (40.98\%), Office clerks (19.85\%), Utility workers (29.9\%), and Manual laborers (9.28\%). Descriptive statistics of demographic data for the study participants were evaluated and are shown in table 1.

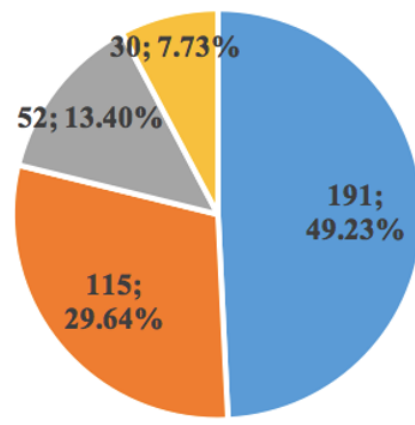

$-20-29=30-39=40-49=50-59$

Figure 3: Age distribution, $n=388$.

The confidence interval in table 2 tells where the true mean of the thumb opposition strength measure in the whole population showed in table 2 . In stage 5 right the mean is 4.14 to $4.42 \mathrm{~kg}$, Left 3.79 to $4.04 \mathrm{~kg}$. Stage 6 right 2.80 to $3.02 \mathrm{~kg}$, Left 2.48 to $2.67 \mathrm{~kg}$. Stage 9 right 3.23 to $3.40 \mathrm{~kg}$, left 3.17 to $3.34 \mathrm{~kg}$. 


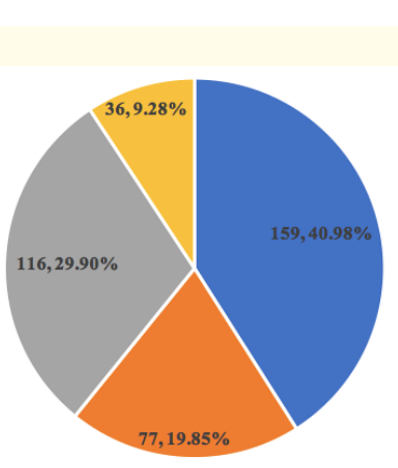

- Medical Professionals = Office Clerks "Utility Workers "Manual Laborers

Figure 4: Occupation distribution, $\mathrm{n}=388$.

Comparative Analysis of the Stages of Thumb Opposition Strength Measure in table 3.1, the P-Values are less than 0.05. This suggests that there are significant differences of means of thumb opposition strength measures in at least two stages in right and left hands. The post-hoc analysis in table 3.2 identifies the significant differences among the pairs of stages. It show all Tukey HSD P-value are significant with $<0.05$. This tells that all the pairs of stages are significantly different. Based on table 3.1 and 3.2, it is implied that Stage 5 got the highest measure in both right and left hands, while Stage 6 got the lowest measures in both hands.

\begin{tabular}{|c|c|c|c|c|}
\hline \multicolumn{2}{|l|}{ 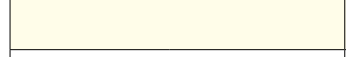 } & Male & Female & Total \\
\hline \multicolumn{2}{|l|}{ n (\%) } & $233(60.05)$ & $155(39.95)$ & $388(100.00)$ \\
\hline \multicolumn{2}{|l|}{ Mean Age } & $34.76(9.02)$ & $29.28(7.23)$ & 32.57 (8.77) \\
\hline \multirow{4}{*}{$\begin{array}{l}\text { Age Groups, } \\
\text { n (\%) }\end{array}$} & $20-29$ & $83(35.62)$ & $108(69.68)$ & 191 (49.23) \\
\hline & $30-39$ & $83(35.62)$ & $32(20.65)$ & $115(29.64)$ \\
\hline & $40-49$ & $44(18.88)$ & $8(5.16)$ & $52(13.40)$ \\
\hline & $50-59$ & $23(9.87)$ & $7(4.52)$ & $30(7.73)$ \\
\hline \multirow{3}{*}{$\begin{array}{l}\text { Hand } \\
\text { Dominance, } \\
\text { n (\%) }\end{array}$} & Right & 204 (87.55) & $138(89.03)$ & 342 (88.14) \\
\hline & Left & $28(12.02)$ & $15(9.68)$ & $43(11.08)$ \\
\hline & Both & $(0.43)$ & $2(1.29)$ & $3(0.77)$ \\
\hline \multirow{4}{*}{$\mid \begin{array}{l}\text { Occupa- } \\
\text { tions, } \mathrm{n}(\%)\end{array}$} & \begin{tabular}{|c|} 
Medical \\
Profession- \\
als \\
\end{tabular} & 67 (28.76) & 92 (59.35) & 159 (40.98) \\
\hline & Office Clerks & 31 (13.30) & $46(29.68)$ & 77 (19.85) \\
\hline & $\begin{array}{c}\text { Utility } \\
\text { Workers }\end{array}$ & 99 (42.49) & 17 (10.97) & $116(29.90)$ \\
\hline & $\begin{array}{l}\text { Manual } \\
\text { Laborers }\end{array}$ & $36(15.45)$ & $0(0.00)$ & $36(9.28)$ \\
\hline \multicolumn{2}{|l|}{ BMI } & $26.30(9.71)$ & $23.37(4.75)$ & $25.13(8.22)$ \\
\hline \multicolumn{2}{|l|}{ Quick DASH } & 2.75 (6.87) & $3.65(6.43)$ & $3.11(6.70)$ \\
\hline
\end{tabular}

Table 1: The demographic data, $\mathrm{n}=388$.

Note: Values presented as mean (standard deviation) unless otherwise stated.

\begin{tabular}{|c|c|c|c|c|c|}
\hline \multicolumn{3}{|c|}{ Thumb Opposition Strength Measure in kilogram } & Male, $n=233$ & Female, $n=155$ & Total, $\mathrm{n}=\mathbf{3 8 8}$ \\
\hline \multirow{8}{*}{$\begin{array}{l}\text { Stage 5: Ring } \\
\text { Finger }\end{array}$} & \multirow{4}{*}{ Right } & Mean & 4.88 & 3.38 & 4.28 \\
\hline & & SD & 1.26 & 1.04 & 1.38 \\
\hline & & SE Mean & 0.082 & 0.083 & 0.0703 \\
\hline & & 95\% Confidence Interval & $(4.72,5.04)$ & $(3.22,3.55)$ & $(4.14,4.42)$ \\
\hline & \multirow{4}{*}{ Left } & Mean & 4.45 & 3.12 & 3.92 \\
\hline & & SD & 1.21 & 0.79 & 1.25 \\
\hline & & SE Mean & 0.079 & 0.063 & 0.0633 \\
\hline & & 95\% Confidence Interval & $(4.30,4.61)$ & $(2.99,3.24)$ & $(3.79,4.04)$ \\
\hline \multirow{8}{*}{$\begin{array}{l}\text { Stage 6: } \\
\text { Little Finger }\end{array}$} & \multirow{4}{*}{ Right } & Mean & 3.37 & 2.21 & 2.91 \\
\hline & & SD & 1.08 & 0.69 & 1.10 \\
\hline & & SE Mean & 0.071 & 0.055 & 0.0557 \\
\hline & & 95\% Confidence Interval & $(3.23,3.51)$ & $(2.10,2.32)$ & $(2.80,3.02)$ \\
\hline & \multirow{4}{*}{ Left } & Mean & 2.95 & 2.02 & 2.58 \\
\hline & & SD & 0.95 & 0.60 & 0.94 \\
\hline & & SE Mean & 0.062 & 0.048 & 0.0479 \\
\hline & & 95\% Confidence Interval & $(2.82,3.07)$ & $(1.93,2.12)$ & $(2.48,2.67)$ \\
\hline
\end{tabular}




\begin{tabular}{|c|c|c|c|c|c|}
\hline \multirow{8}{*}{$\begin{array}{l}\text { Stage 9: MCP } \\
\text { Little Finger }\end{array}$} & \multirow{4}{*}{ Right } & Mean & 3.66 & 2.80 & 3.32 \\
\hline & & SD & 0.82 & 0.60 & 0.85 \\
\hline & & SE Mean & 0.054 & 0.048 & 0.0432 \\
\hline & & 95\% Confidence Interval & $(3.56,3.77)$ & $(2.71,2.90)$ & $(3.23,3.40)$ \\
\hline & \multirow{4}{*}{ Left } & Mean & 3.60 & 2.74 & 3.25 \\
\hline & & SD & 0.82 & 0.52 & 0.83 \\
\hline & & SE Mean & 0.053 & 0.042 & 0.0420 \\
\hline & & $95 \%$ Confidence Interval & $(3.49,3.70)$ & $(2.66,2.82)$ & $(3.17,3.34)$ \\
\hline
\end{tabular}

Table 2: The descriptive statistics of thumb opposition strength measure (in kilogram) in each stage.

\begin{tabular}{|l|c|c|c|c|c|c|}
\hline \multirow{2}{*}{} & \multicolumn{3}{|c|}{ Right } & \multicolumn{2}{c|}{ Left } \\
\cline { 2 - 7 } & $\begin{array}{c}\text { Stage 5: } \\
\text { Ring Finger }\end{array}$ & $\begin{array}{c}\text { Stage 6: } \\
\text { Little Finger }\end{array}$ & $\begin{array}{c}\text { Stage 9: } \\
\text { MCP Little } \\
\text { Finger }\end{array}$ & $\begin{array}{c}\text { Stage 5: } \\
\text { Ring Finger }\end{array}$ & $\begin{array}{c}\text { Stage 6: } \\
\text { Little Finger }\end{array}$ & $\begin{array}{c}\text { Stage 9: } \\
\text { MCP Little } \\
\text { Finger }\end{array}$ \\
\hline Mean & 4.28 & 2.91 & 3.32 & 3.92 & 2.58 & 3.25 \\
\hline SD & 1.38 & 1.10 & 0.85 & 1.25 & 0.94 & 0.83 \\
\hline F-Value (P-Value) & \multicolumn{3}{|c|}{$409.85(<0.001)^{* *}$} \\
\hline
\end{tabular}

Table 3.1: Comparative analysis of the stages of thumb opposition strength measure using one-way repeated measures ANOVA. Note: **: Significant at 0.05 .

\begin{tabular}{|c|c|c|c|}
\hline \multirow{4}{*}{ Right } & Pairs & Tukey HSD & Tukey HSD \\
& Q statistic & P-Value \\
\hline \multirow{3}{*}{ Left } & Stage 5 vs Stage 6 & 23.9450 & $0.001^{* *}$ \\
\cline { 2 - 4 } & Stage 5 vs Stage 9 & 16.7482 & $0.001^{* *}$ \\
\cline { 2 - 4 } & Stage 6 vs Stage 9 & 7.1968 & $0.001^{* *}$ \\
\hline \multirow{3}{*}{} & Stage 5 vs Stage 6 & 25.8679 & $0.001^{* *}$ \\
\cline { 2 - 4 } & Stage 5 vs Stage 9 & 12.8221 & $0.001^{* *}$ \\
\cline { 2 - 4 } & Stage 6 vs Stage 9 & 13.0458 & $0.016^{* *}$ \\
\hline
\end{tabular}

Table 3.2: Post-hoc analysis using Tukey HSD test. Note: ${ }^{* *}$ : Significant at 0.05 .

Correlation analysis of handedness and thumb opposition strength measures using point-biserial correlation in table 4 shows that the P-Values are greater than 0.05 on all stages. This explains that handedness and thumb opposition strength measures are not significantly associated.

Pearson $r$ product moment correlation in table 5 was used to measure correlation between body mass index (BMI) and quick

\begin{tabular}{|c|c|c|c|}
\hline & & & Handedness \\
\hline \multirow{4}{*}{$\begin{array}{l}\text { Stage 5: } \\
\text { Ring } \\
\text { Finger }\end{array}$} & \multirow[t]{2}{*}{ Right } & $\begin{array}{l}\text { Point Biserial } \\
\text { Correlation } r\end{array}$ & 0.032 \\
\hline & & P-Value & 0.530 \\
\hline & \multirow[t]{2}{*}{ Left } & $\begin{array}{l}\text { Point Biserial } \\
\text { Correlation } r\end{array}$ & -0.028 \\
\hline & & P-Value & 0.583 \\
\hline \multirow{4}{*}{$\begin{array}{l}\text { Stage 6: } \\
\text { Little } \\
\text { Finger }\end{array}$} & \multirow{2}{*}{ Right } & $\begin{array}{l}\text { Point Biserial } \\
\text { Correlation } r\end{array}$ & 0.007 \\
\hline & & P-Value & 0.888 \\
\hline & \multirow[t]{2}{*}{ Left } & $\begin{array}{l}\text { Point Biserial } \\
\text { Correlation } r\end{array}$ & 0.003 \\
\hline & & P-Value & 0.956 \\
\hline \multirow{4}{*}{$\begin{array}{l}\text { Stage 9: } \\
\text { MCP } \\
\text { Little } \\
\text { Finger }\end{array}$} & \multirow[t]{2}{*}{ Right } & $\begin{array}{l}\text { Point Biserial } \\
\text { Correlation } r\end{array}$ & -0.015 \\
\hline & & P-Value & 0.775 \\
\hline & \multirow[t]{2}{*}{ Left } & $\begin{array}{l}\text { Point Biserial } \\
\text { Correlation } r\end{array}$ & -0.053 \\
\hline & & P-Value & 0.297 \\
\hline
\end{tabular}

Table 4: The correlation analysis of handedness and thumb opposition strength measures using point-biserial correlation. Note: **: Significant at 0.05 . 
DASH. Table 6 shows that the BMI of stage 5 left hand and stage 6 right hand are statistically significant, while the rest are not. The significant correlation coefficients suggest that BMI and thumb opposition strength measures are positively associated in stage 5 left hand and stage 6 right hand. This means that an increase in BMI is

\begin{tabular}{|c|c|c|c|c|}
\hline & & & BMI & $\begin{array}{l}\text { Quick } \\
\text { DASH }\end{array}$ \\
\hline \multirow{4}{*}{$\begin{array}{l}\text { Stage 5: } \\
\text { Ring } \\
\text { Finger }\end{array}$} & \multirow[t]{2}{*}{ Right } & $\begin{array}{c}\text { Pearson Correlation } \\
\text { Coefficient } \mathrm{r}\end{array}$ & 0.054 & 0.035 \\
\hline & & P-Value & 0.285 & 0.489 \\
\hline & \multirow[t]{2}{*}{ Left } & $\begin{array}{c}\text { Pearson Correlation } \\
\text { Coefficient } r\end{array}$ & 0.107 & -0.026 \\
\hline & & P-Value & $0.034^{* *}$ & 0.609 \\
\hline \multirow{4}{*}{$\begin{array}{l}\text { Stage 6: } \\
\text { Little } \\
\text { Finger }\end{array}$} & \multirow[t]{2}{*}{ Right } & $\begin{array}{c}\text { Pearson Correlation } \\
\text { Coefficient } r\end{array}$ & 0.138 & 0.007 \\
\hline & & P-Value & $0.006^{* *}$ & 0.898 \\
\hline & \multirow[t]{2}{*}{ Left } & $\begin{array}{c}\text { Pearson Correlation } \\
\text { Coefficient } \mathrm{r}\end{array}$ & 0.057 & -0.014 \\
\hline & & P-Value & 0.265 & 0.777 \\
\hline \multirow{4}{*}{$\begin{array}{l}\text { Stage 7: } \\
\text { MCP Little } \\
\text { Finger }\end{array}$} & \multirow[t]{2}{*}{ Right } & $\begin{array}{c}\text { Pearson Correlation } \\
\text { Coefficient } r\end{array}$ & 0.090 & -0.067 \\
\hline & & P-Value & 0.075 & 0.191 \\
\hline & \multirow[t]{2}{*}{ Left } & $\begin{array}{c}\text { Pearson Correlation } \\
\text { Coefficient } \mathrm{r}\end{array}$ & 0.070 & -0.002 \\
\hline & & P-Value & 0.170 & 0.962 \\
\hline
\end{tabular}

Table 5: The correlation analysis of BMI and quick DASH scores and thumb opposition strength measures using Pearson $r$ product moment correlation.

Note: **: Significant at 0.05 .

The correlation analysis of age and thumb opposition strength measures in table 6 shows that the P-values in all stages are less than 0.05 except for the stage 9 left hand. This tells that age and thumb opposition strength measures are significantly associated in right and left hands in stage 5, right and left hands in stage 6, and right hand in stage 9 . In these significantly associated variables, the coefficients suggest that they are positively related. It means that if the age of the person increases, the strength of his/her thumb also increases.

Table 7 shows that male and female thumb opposition strength measures are significantly different since the P-Values are less than associated in an increase of thumb opposition strength measures in left ring finger and right little finger. On the other hand, the table shows that the P-Values in the Quick DASH scores are not statistically significant. This tells that Quick DASH scores and thumb opposition strength measures are not significantly associated.

\begin{tabular}{|c|c|c|c|}
\hline & & & Age \\
\hline \multirow{2}{*}{ Stage 5: } & \multirow[t]{2}{*}{ Right } & $\begin{array}{c}\text { Pearson Correlation } \\
\text { Coefficient } \mathrm{r}\end{array}$ & 0.278 \\
\hline & & P-Value & $<0.001^{* *}$ \\
\hline \multirow[t]{2}{*}{$\begin{array}{l}\text { Ring } \\
\text { Finger }\end{array}$} & \multirow[t]{2}{*}{ Left } & $\begin{array}{c}\text { Pearson Correlation } \\
\text { Coefficient } r\end{array}$ & 0.253 \\
\hline & & P-Value & $<0.001^{* *}$ \\
\hline & \multirow[t]{2}{*}{ Right } & $\begin{array}{c}\text { Pearson Correlation } \\
\text { Coefficient } r\end{array}$ & 0.323 \\
\hline & & P-Value & $<0.001^{* *}$ \\
\hline \multirow[t]{2}{*}{$\begin{array}{l}\text { Little } \\
\text { Finger }\end{array}$} & \multirow[t]{2}{*}{ Left } & $\begin{array}{c}\text { Pearson Correlation } \\
\text { Coefficient } r\end{array}$ & 0.223 \\
\hline & & P-Value & $<0.001^{* *}$ \\
\hline \multirow{4}{*}{$\begin{array}{l}\text { MCP } \\
\text { Little } \\
\text { Finger }\end{array}$} & \multirow[t]{2}{*}{ Right } & $\begin{array}{c}\text { Pearson Correlation } \\
\text { Coefficient } \mathrm{r}\end{array}$ & 0.179 \\
\hline & & P-Value & $<0.001^{* *}$ \\
\hline & \multirow[t]{2}{*}{ Left } & $\begin{array}{c}\text { Pearson Correlation } \\
\text { Coefficient } r\end{array}$ & 0.043 \\
\hline & & P-Value & 0.402 \\
\hline
\end{tabular}

Table 6: The correlation analysis of age and thumb opposition strength measures Pearson r product moment correlation.

Note: **: Significant at 0.05 .
0.05. The sample means imply that males have higher thumb opposition strength measures in all stages left and right hands compared to those of the females. Significant difference of means is observed in stage 5 right hand in males. The sample means suggest that male stage 5 right dominant hand have higher thumb opposition strength measures than the non-dominant. The rest of the stages in males are observed to have no significant difference of means of thumb opposition strength measures between dominant and non-dominant hand. That is, the strengths of the thumb opposition are comparable between dominant and non-dominant hand. While there are no significant differences in the thumb opposition 


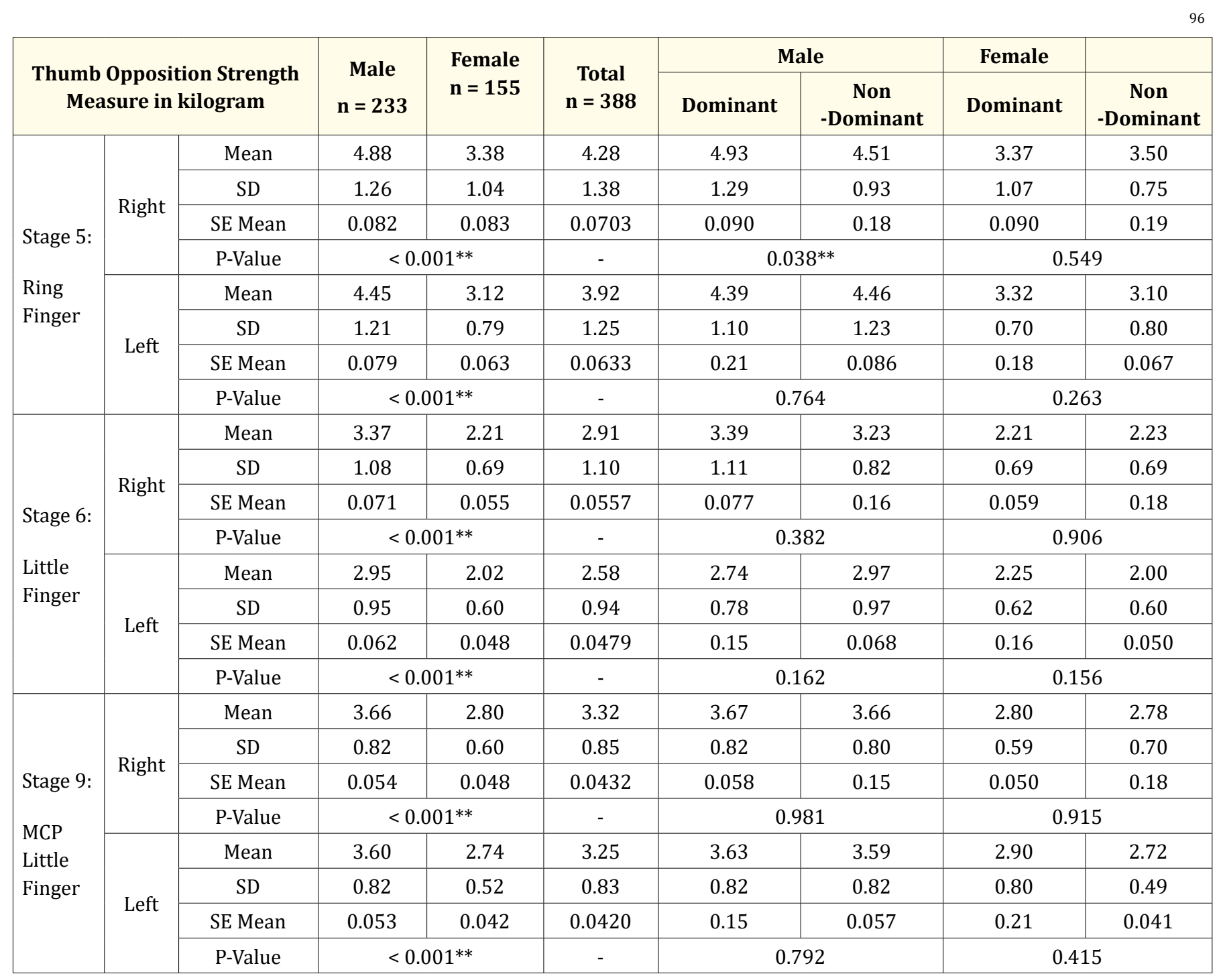

Table 7: Comparative analysis of thumb opposition strength measures among male and female adults and dominant and non-dominant male and female adults.

Note: **: Significant at 0.05 .

strength measures between females dominant and non-dominant hand. This implies that the strengths of the thumb opposition are comparable between dominant and non-dominant hand of females.

Comparative analysis of the thumb opposition strength measures among age groups in table 8.1, the P-Values are less than 0.05 except in stage 9 left hand. These are said to be significant. These tell that there are significant differences of means of thumb opposition strength measures in at least two age groups in stage 5 right and left hands, stage 6 right and left hands and stage 9 right hand. The post-hoc analysis in table 8.2 identifies the significant differences among the pairs of age groups. The lowest measures are generally observed in younger age groups in stage 5 right and left hands, stage 6 right and left hands, and stage 9 right hand. 


\begin{tabular}{|c|c|c|c|c|c|c|}
\hline & & & \multicolumn{4}{|c|}{ Age Groups } \\
\hline & & & $20-29, n=191$ & $30-39, n=115$ & $40-49, n=52$ & $50-59, n=30$ \\
\hline \multirow{6}{*}{$\begin{array}{l}\text { Stage 5: } \\
\text { Ring Finger }\end{array}$} & \multirow{3}{*}{ Right } & Mean & 3.942 & 4.376 & 5.019 & 4.808 \\
\hline & & SD & 1.237 & 1.342 & 1.444 & 1.650 \\
\hline & & F-Value (P-Value) & \multicolumn{4}{|c|}{$11.20(<0.001)^{* *}$} \\
\hline & \multirow{3}{*}{ Left } & Mean & 3.634 & 3.983 & 4.639 & 4.242 \\
\hline & & SD & 1.077 & 1.269 & 1.362 & 1.406 \\
\hline & & F-Value (P-Value) & \multicolumn{4}{|c|}{$10.63(<0.001)^{* *}$} \\
\hline \multirow{6}{*}{$\begin{array}{l}\text { Stage 6: } \\
\text { Little Finger }\end{array}$} & \multirow{3}{*}{ Right } & Mean & 2.592 & 2.989 & 3.538 & 3.492 \\
\hline & & SD & 0.947 & 1.044 & 1.203 & 1.270 \\
\hline & & F-Value (P-Value) & \multicolumn{4}{|c|}{$15.64(<0.001)^{* *}$} \\
\hline & \multirow{3}{*}{ Left } & Mean & 2.380 & 2.659 & 2.976 & 2.833 \\
\hline & & SD & 0.943 & 0.897 & 0.912 & 0.901 \\
\hline & & F-Value (P-Value) & \multicolumn{4}{|c|}{$7.23(<0.001)^{* *}$} \\
\hline \multirow{6}{*}{$\begin{array}{l}\text { Stage 9: } \\
\text { MCP Little } \\
\text { Finger }\end{array}$} & \multirow{3}{*}{ Right } & Mean & 3.165 & 3.394 & 3.596 & 3.542 \\
\hline & & SD & 0.813 & 0.820 & 0.886 & 0.981 \\
\hline & & F-Value (P-Value) & \multicolumn{4}{|c|}{$5.05(0.002)^{* *}$} \\
\hline & \multirow{3}{*}{ Left } & Mean & 3.200 & 3.300 & 3.394 & 3.175 \\
\hline & & SD & 0.813 & 0.808 & 0.823 & 0.983 \\
\hline & & F-Value (P-Value) & \multicolumn{4}{|c|}{$0.98(0.403)$} \\
\hline
\end{tabular}

Table 8.1: Comparative analysis of the thumb opposition strength measures among age groups using one-way ANOVA. Note: **: Significant at 0.05 .

\section{Discussion}

Function of the thumb is complex compared to other fingers. It involves Flexion, Extension, palmar abduction, retroposition, adduction, and opposition [1]. Among these, thumb opposition is the hallmark of human hand function [2]. It is the vital in providing motion and strength for both pinch and grasp. The opposition is the result of two types of movements: angulatory motion and rotary motion [3]. Opposition of the thumb results from abduction at the carpometacarpal joint and flexion and rotation of both the CMC and metacarpophalangeal joints. Active muscles include the abductor pollicis brevis, the opponens pollicis, and the superficial head of the flexor pollicis brevis. Indirectly Abductor pollicis longus and the extensor pollicis brevis contribute to opposition [4].

Thumb opposition is affected in certain conditions and was given importance to such.
In a study by Bhavuk Garg., et al. of 22 patients, they measured the thumb oppositional strength as one of their variable in severe carpal tunnel syndrome patients who underwent carpal tunnel release. Measuring it preoperatively and postoperatively in kilograms using a hand held dynamometer and noted improvement after the carpal tunnel release. They mentioned that in carpal tunnel syndrome thenar atrophy can happen due to involvement of the median nerve and that thumb abduction and opposition will be affected [5].

According to Carrie Swigart on his study in thumb carpometacarpal joint arthritis, patient would complain of pain on the base of the thumb and would complain of functional disability of the hand especially in thumb opposition and pinch grip. Physical examination would include tenderness on the base of the thumb. This is the second most common site affected by primary idiopathic arthritis in the hand behind only the distal joints of the fingers [6]. 


\begin{tabular}{|c|c|c|c|c|}
\hline & & Pairs & $\begin{array}{l}\text { Tukey HSD } \\
\text { Q statistic }\end{array}$ & $\begin{array}{c}\text { Tukey } \\
\text { HSD } \\
\text { P-Value }\end{array}$ \\
\hline \multirow{6}{*}{ Stage 5: } & \multirow{6}{*}{ Right } & 20-29 vs 30-39 & 3.9006 & $0.031^{* *}$ \\
\hline & & $20-29$ vs $40-49$ & 7.3083 & $0.001^{* *}$ \\
\hline & & $20-29$ vs $50-59$ & 4.6808 & $0.006^{* *}$ \\
\hline & & $30-39$ vs $40-49$ & 4.0856 & $0.021^{* *}$ \\
\hline & & $30-39$ vs $50-59$ & 2.2383 & 0.391 \\
\hline & & $40-49$ vs $50-59$ & 0.9765 & 0.898 \\
\hline \multirow{6}{*}{$\begin{array}{l}\text { Ring } \\
\text { Finger }\end{array}$} & \multirow{6}{*}{ Left } & $20-29$ vs $30-39$ & 3.4768 & 0.068 \\
\hline & & $20-29$ vs $40-49$ & 7.5596 & $0.001^{* *}$ \\
\hline & & $20-29$ vs $50-59$ & 3.6402 & 0.051 \\
\hline & & $30-39$ vs $40-49$ & 4.6202 & $0.006^{* *}$ \\
\hline & & $30-39$ vs 50-59 & 1.4854 & 0.696 \\
\hline & & $40-49$ vs $50-59$ & 2.0394 & 0.475 \\
\hline \multirow{12}{*}{ Stage 6} & \multirow{6}{*}{ Right } & $20-29$ vs $30-39$ & 4.5789 & $0.007^{* *}$ \\
\hline & & $20-29$ vs $40-49$ & 8.2303 & $0.001^{* *}$ \\
\hline & & 20-29 vs 50-59 & 6.2312 & $0.001^{* *}$ \\
\hline & & $30-39$ vs $40-49$ & 4.4695 & $0.009^{* *}$ \\
\hline & & $30-39$ vs 50-59 & 3.3329 & 0.087 \\
\hline & & $40-49$ vs $50-59$ & 0.2775 & 0.900 \\
\hline & \multirow{6}{*}{ Left } & $20-29$ vs $30-39$ & 3.6263 & 0.0522 \\
\hline & & $20-29$ vs $40-49$ & 5.8467 & $0.001^{* *}$ \\
\hline & & $20-29$ vs 50-59 & 3.5430 & 0.061 \\
\hline & & $30-39$ vs $40-49$ & 2.9113 & 0.169 \\
\hline & & $30-39$ vs 50-59 & 1.3063 & 0.767 \\
\hline & & 40-49 vs 50-59 & 0.9540 & 0.900 \\
\hline \multirow{6}{*}{$\begin{array}{l}\text { Stage 9: } \\
\text { MCP } \\
\text { Little } \\
\text { Finger }\end{array}$} & \multirow{6}{*}{ Right } & $20-29$ vs $30-39$ & 3.2645 & 0.098 \\
\hline & & 20-29 vs 40-49 & 4.6478 & $0.006^{* *}$ \\
\hline & & 20-29 vs 50-59 & 3.2341 & 0.103 \\
\hline & & $30-39$ vs $40-49$ & 2.0446 & 0.473 \\
\hline & & $30-39$ vs 50-59 & 1.2186 & 0.802 \\
\hline & & $40-49$ vs $50-59$ & 0.4007 & 0.900 \\
\hline
\end{tabular}

Table 8.2: Post-hoc analysis using Tukey HSD test. Note: ${ }^{* *}$ : Significant at 0.05 .

In the study by Durban., et al. on Thumb Function and Electromyography Result after Modified Camitz Tendon Transfer on patients

with severe carpal tunnel syndrome. It mentioned that opposition of the thumb is vital in hand function and that the median nerveinnervated abductor pollicis brevis and opponens pollicis will be unable to flex, abduct and oppose the thumb will be affected. In the study they measured the thumb function using several measurements including Van Wetter Apogee, Kapandji scoring, Electromyography was used to assess Abductor Pollicis Brevis recovery, and a high resolution ultrasound was used to evaluate the activity of the palmaris longus during thumb opposition and abduction [7].

Several tools for measuring thumb opposition were mentioned including the medical Research council using the Manual Muscle Strength Testing to grade the muscle strength in 6 levels. It measures the muscle strength of the functions of the thumb. This measurement involves interobsever variable and it measures qualitatively the muscle strength and has poor sensitivity and reliability [8]. Schreuders., et al. also mentioned another tool which is the Rotterdam intrinsic myometer that measures the intrinsic muscles of the hand. This tool can individually assess the intrinsic muscles of the hand [9]. Another way to measure oppositional function of the thumb was stated by Kapandji which utilizes 10 points to note full oppositional function of the thumb. It involves ten stages which describes the wide course of opposition. And when reaching the $10^{\text {th }}$ stage we consider that thumb opposition is normal [10]. Stage 5,6 , and 9 of Kapandji was used for standardization in this study.

Currently there is no reference stating the quantitative baseline of thumb oppositional strength in healthy individuals using a standardized tool. Thus the Jamar B \& L Pinch Gauge Dynamometer (Sammons Preston Rolyan) (Figure 2) also known as the gold standard in pinch strength (Key, Tip and Palmar) measurement was used in this study. It measures 0 - 60 lbs. in $2.0 \mathrm{lb}$. increments and kilogram scale. Calibration certificate included with accuracy $=0.6 \mathrm{lb}[11]$.

With 388 individuals included in the study, it was noted that the mean thumb opposition strength in stage 5 right is 4.14 to $4.42 \mathrm{~kg}$, Left 3.79 to $4.04 \mathrm{~kg}$. Stage 6 right 2.80 to $3.02 \mathrm{~kg}$, left 2.48 to $2.67 \mathrm{~kg}$. Stage 9 right 3.23 to $3.40 \mathrm{~kg}$, left 3.17 to $3.34 \mathrm{~kg}$. There was significant difference between the 3 designated stages of Kapandji (Stage $5,6,9)$ wherein, stage 5 got the highest measure in both right and left hands, while stage 6 got the lowest measures in both hands. 
Generally, males have higher strength than females and that hand dominance has no significant correlation to oppositional strength of the thumb. However, only in males' stage 5 where it showed a significant difference where the dominant hand was stronger. Age has a positive correlation with thumb opposition strength except on stage 9 Left. Lower measures are generally observed in younger age groups. BMI and Dash score showed no significant correlation except on stage 5 left and stage 6 right. This means that an increase in BMI is associated in an increase of thumb opposition strength measures in left stage 5 and right stage 6 .

A limitation of this study was that the data collection was done during COVID 19 pandemic. Recruited subjects could have been more diverse if taken from public places wherein diverse population groups are present. Elderly population was meant to be included in the study however due to the pandemic situation, none were recruited because of restrictions in this age group. Nonetheless the data gathered were representative of different ages and occupations in our society. Also, calibration of the dynamometer should be checked regularly, because an inaccurate device might lead to significant differences in the results.

\section{Conclusion}

Baseline reference for thumb opposition strength is of significance considering that this function of the thumb is vital and it is involved in several conditions. This data will be of great importance as a quantitative measure for therapeutic assessment and that it can be used as screening measure for susceptible individuals. The mean strength in Kapandji stage 5 right is 4.14 to $4.42 \mathrm{~kg}$, Left 3.79 to $4.04 \mathrm{~kg}$. Kapandji stage 6 right 2.80 to $3.02 \mathrm{~kg}$, Left 2.48 to 2.67 $\mathrm{kg}$. Kapandji stage 9 right 3.23 to $3.40 \mathrm{~kg}$, left 3.17 to $3.34 \mathrm{~kg}$. Also, in all the hand parameters, men were stronger than females. Hand dominance in general has no significant correlation to thumb opposition strength.

\section{Conflict of Interest}

There is no conflict of interests exist nor any financial interest.

\section{Bibliography}

1. Barakat MJ., et al. "The range of movement of the thumb". Hand New York Journal 8.2 (2013): 179-182.
2. Bunnell S. "Opposition of the thumb". Journal of Bone and Joint Surgery 20.2 (1938): 269-284.

3. Söderberg L. "Repair of failing opposition of the thumb". Acta Orthopaedica Scandinavica 22 (1952): 237-248.

4. Cooney WP., et al. "Opposition of the thumb: an anatomic and biomechanical study of tendon transfers". Journal of Hand Surgery American 9.6 (1984): 777-786.

5. Garg B., et al. "Thumb opposition recovery following surgery for severe carpal tunnel syndrome: A clinical, radiological, and electrophysiological pilot study". Journal of Hand Surgery American 44.2 (2019): e1-e5.

6. Swigart CR. "Arthritis of the base of the thumb". Current Review in Musculoskeletal Medicine 1.2 (2008): 142-146.

7. Durban CM., et al. "Thumb function and electromyography result after modified Camitz tendon transfer". The Journal of Hand Surgery Asian-Pacific 22.3 (2017): 275-280.

8. Brandsma JW., et al. "Manual muscle strength testing: intraobserver and interobserver reliabilities for the intrinsic muscles of the hand". The Journal of Hand Therapy 8.3 (1995): 185-190.

9. Schreuders TA., et al. "Strength measurements of the intrinsic hand muscles: a review of the development and evaluation of the Rotterdam intrinsic hand myometer". The Journal of Hand Therapy 19.4 (2006): 393-401.

10. Kapandji AI. "Clinical evaluation of the thumb's opposition". Journal of Hand Therapy 5 (1992): 102-116.

11. Handog PB and Pua JC. "Grip and pinch strength in healthy adult Filipinos- A baseline study". Philippine Journal of Orthopaedics 33.1 (2014): 47-51.

Volume 4 Issue 6 June 2021

(C) All rights are reserved by Charles Andrew $\mathrm{R}$ Chu -Santos and Precious Grace B Handog. 